\title{
New Chiral Building Blocks from Tetrabromocyclopropene
}

Phillip M. Pelphrey, Khalil Abboud and Dennis L. Wright

\section{Supplemental Information}

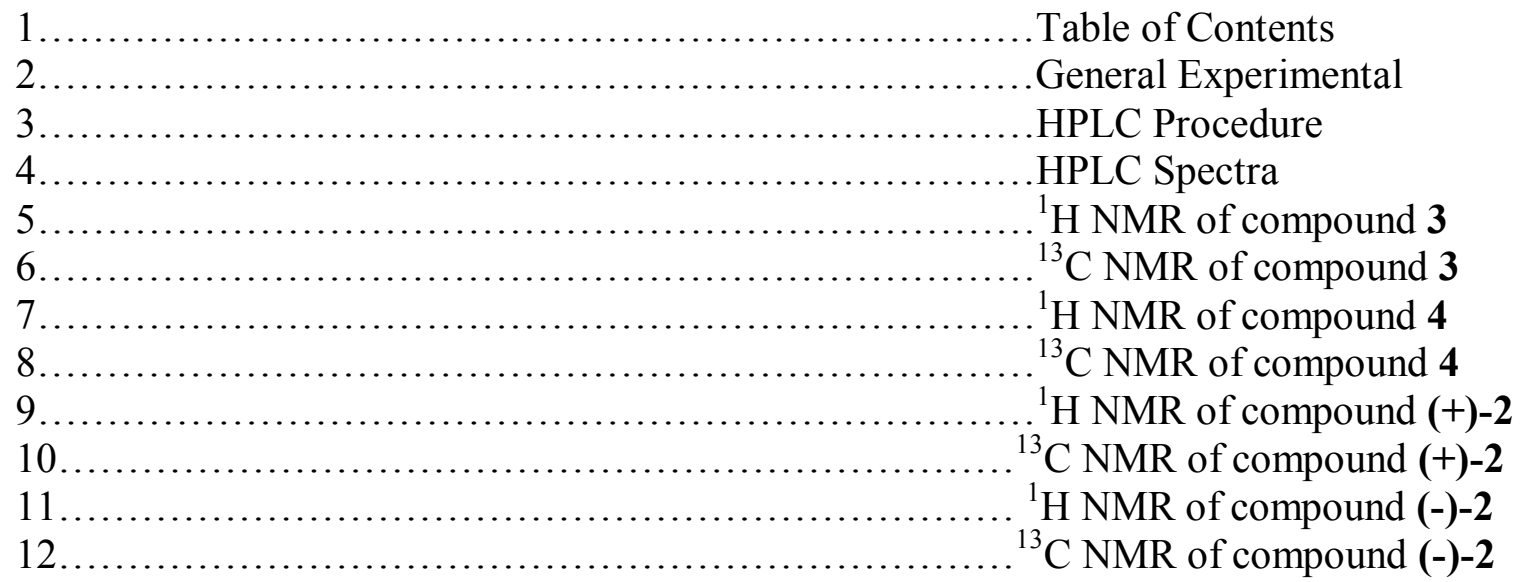




\section{General Experimental}

All reactions were performed under an atmosphere of argon in flame-dried glassware. Starting materials were weighed out in a dry box under a nitrogen atmosphere. Dichloromethane was distilled from calcium hydride. All other materials were obtained from commercial sources and used without any further purification. 


\section{HPLC Procedure}

Enantiomeric excess of the derived endo alcohols were determined on a Hewlett Packard Series 1100 HPLC using a Daicel Chemical Industries, LTD. Chiralcel OJ-H chiral column. (+)-2 and (-)2 were reduced to the respective alcohols using standard Luche conditions. ${ }^{1}$ Separations were performed in hexanes:isopropanol (97:3) at a column flow rate of $0.85 \mathrm{~mL} / \mathrm{min}$ with detection at $254 \mathrm{~nm}$.

${ }^{1}$ Orugunty, R.S., Wright, D.L., Battiste, M.A., Helmich, R.J. and Abboud, K., J. Org. Chem., 2004, 69, 406-16. 

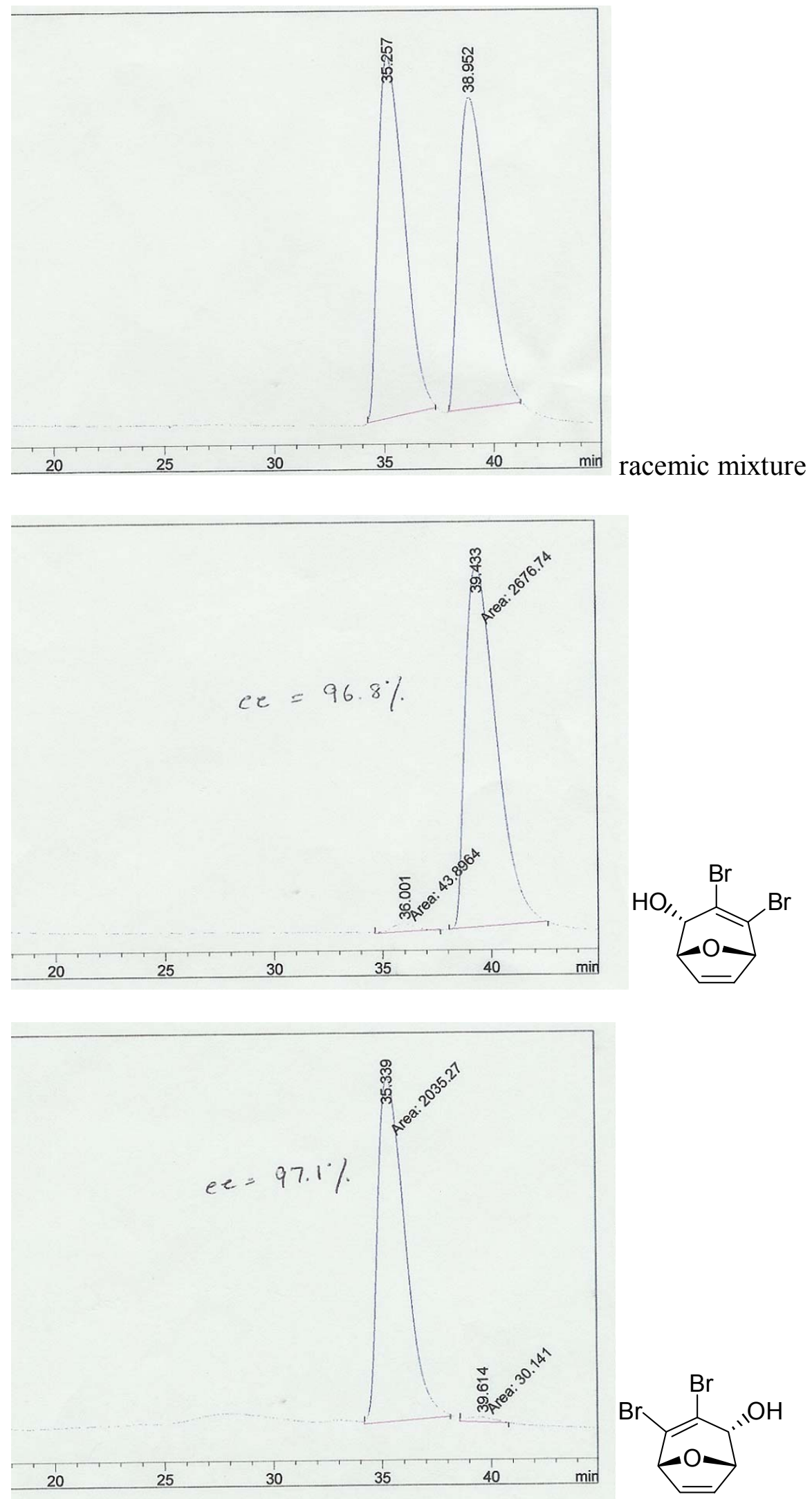<smiles>O[C@@H]1C(Br)=C(Br)C2C=CC1O2</smiles> 

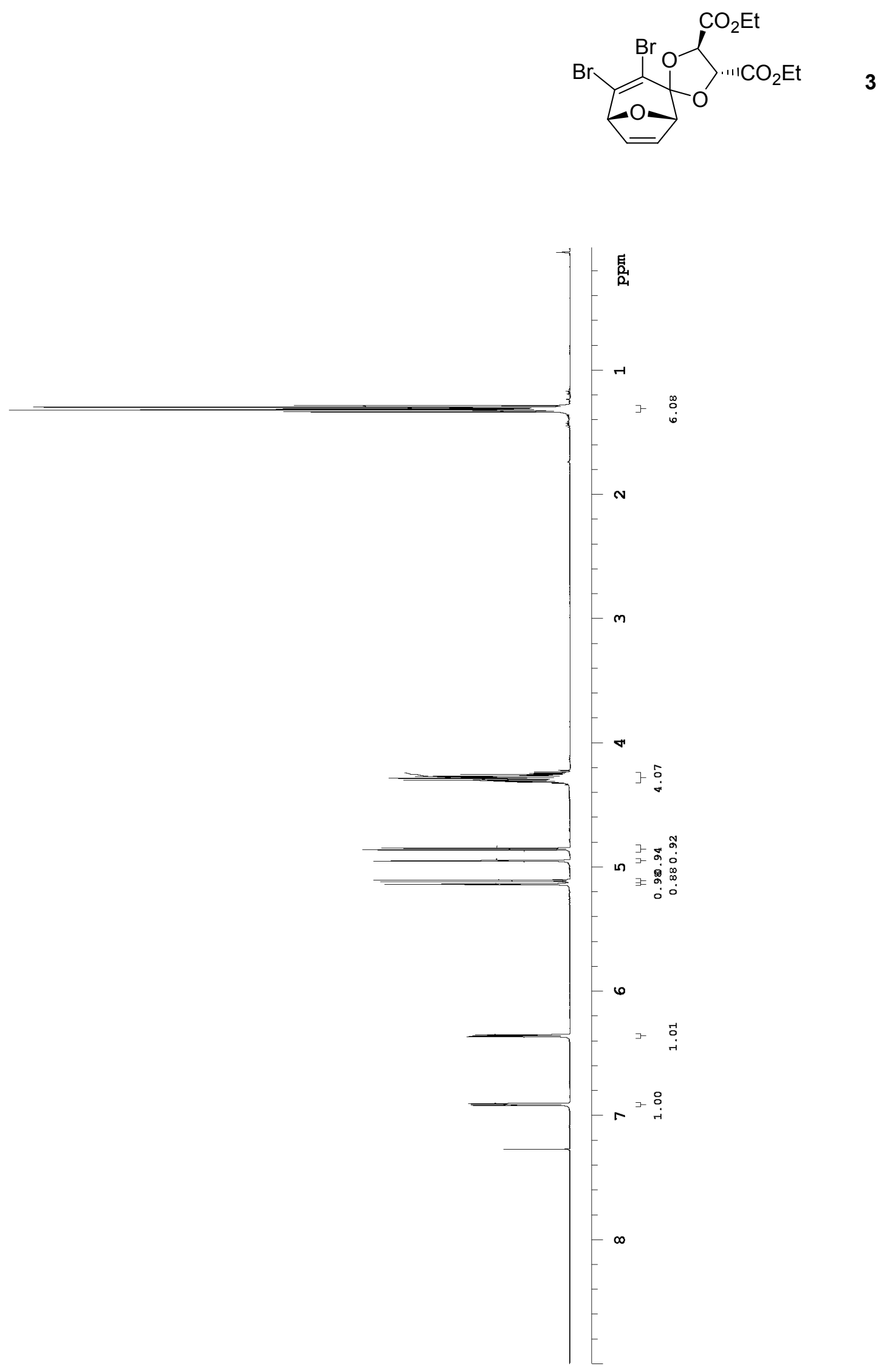


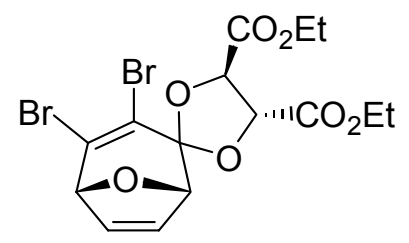

3

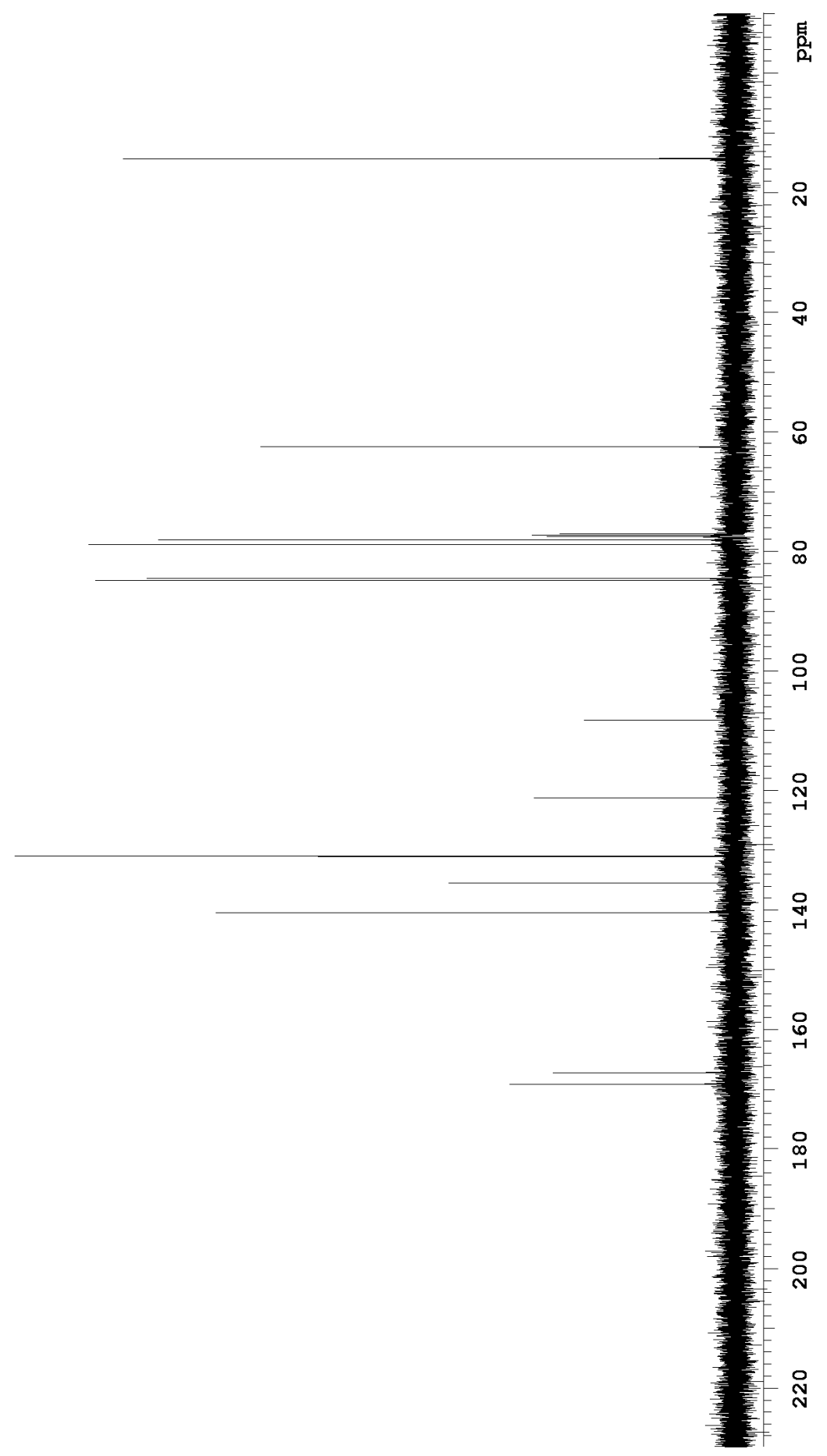

6 

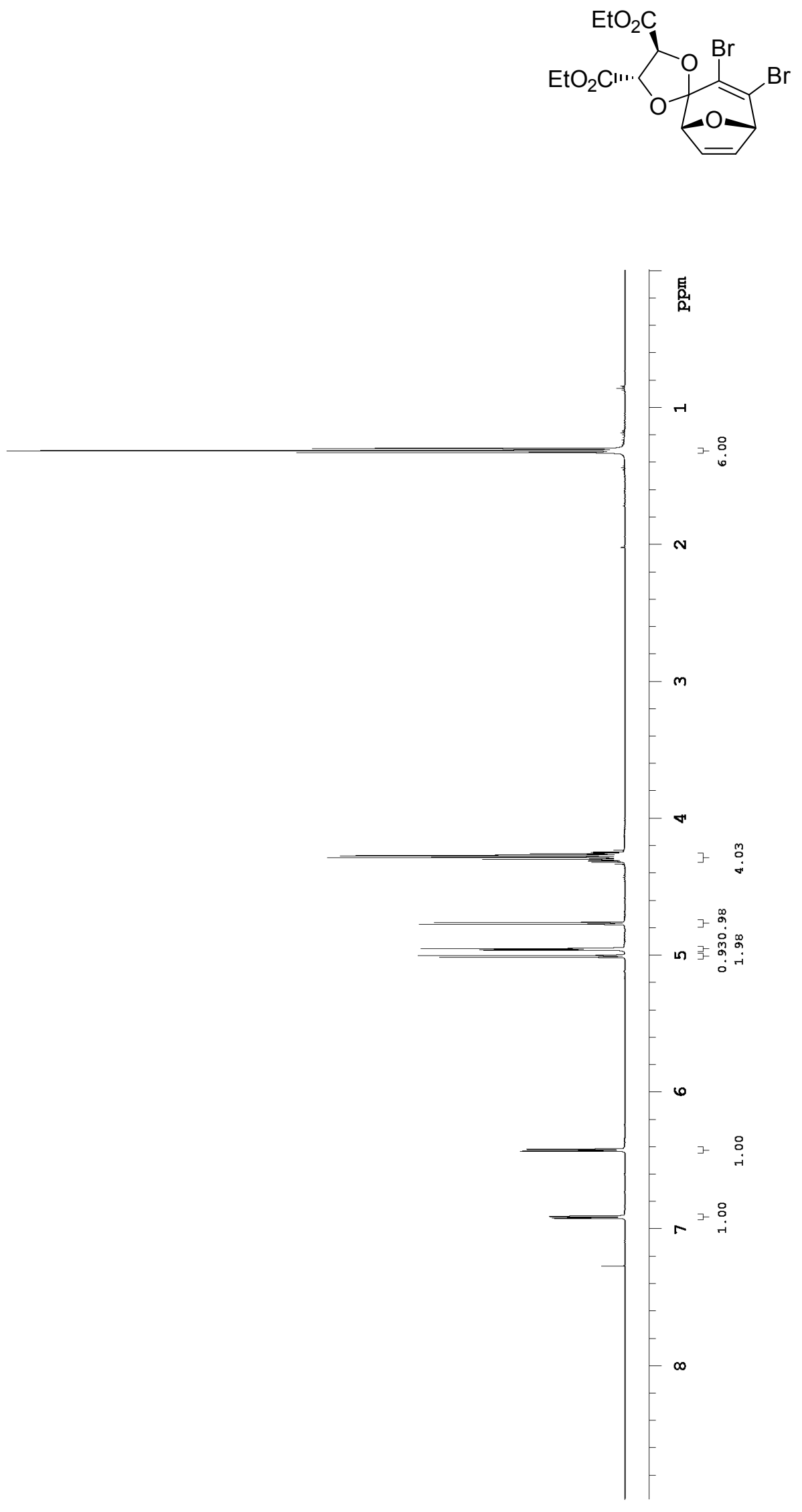


$$
\mid
$$




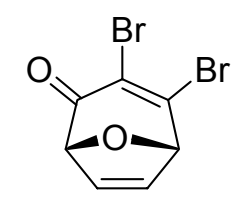

(+)-2

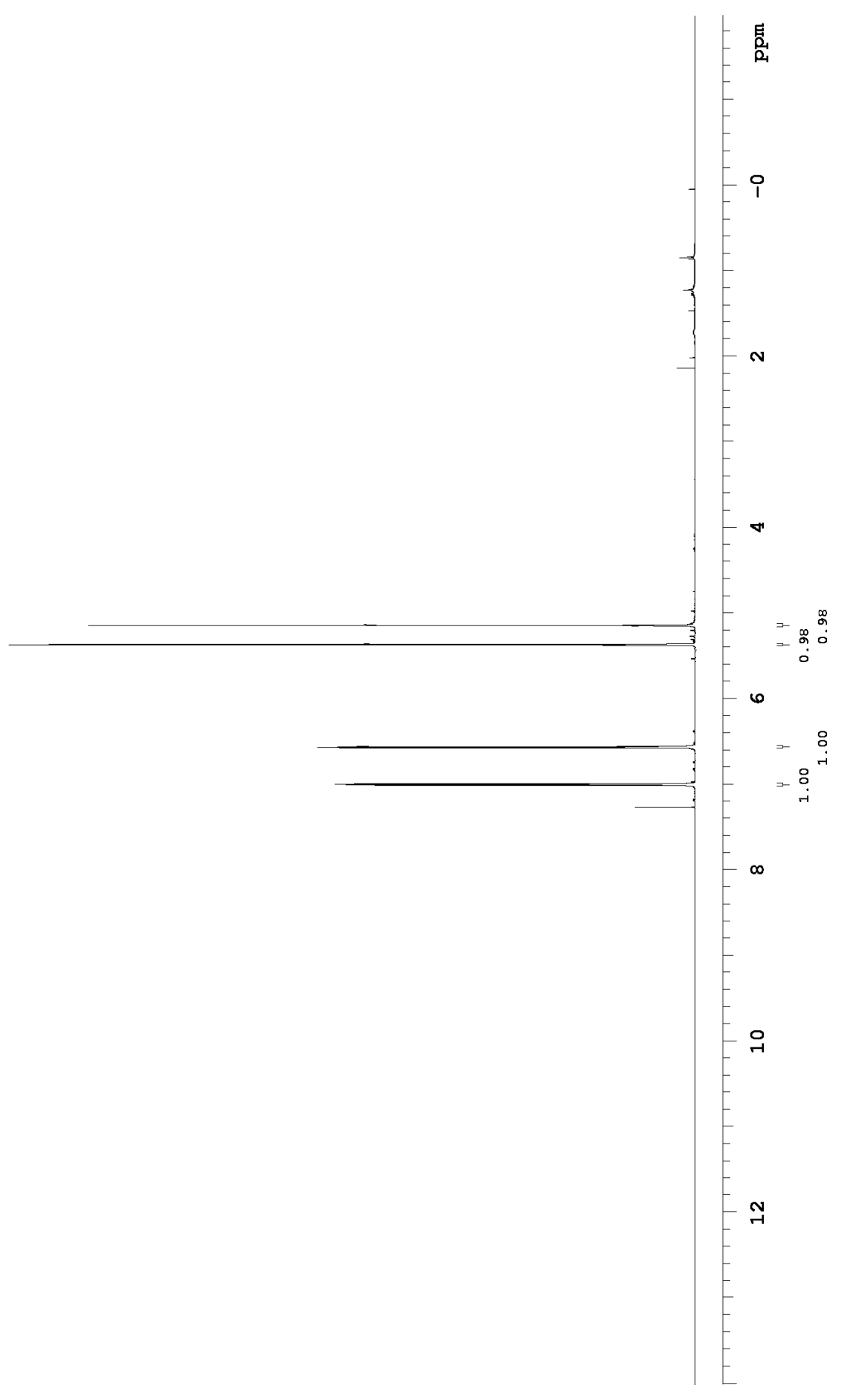



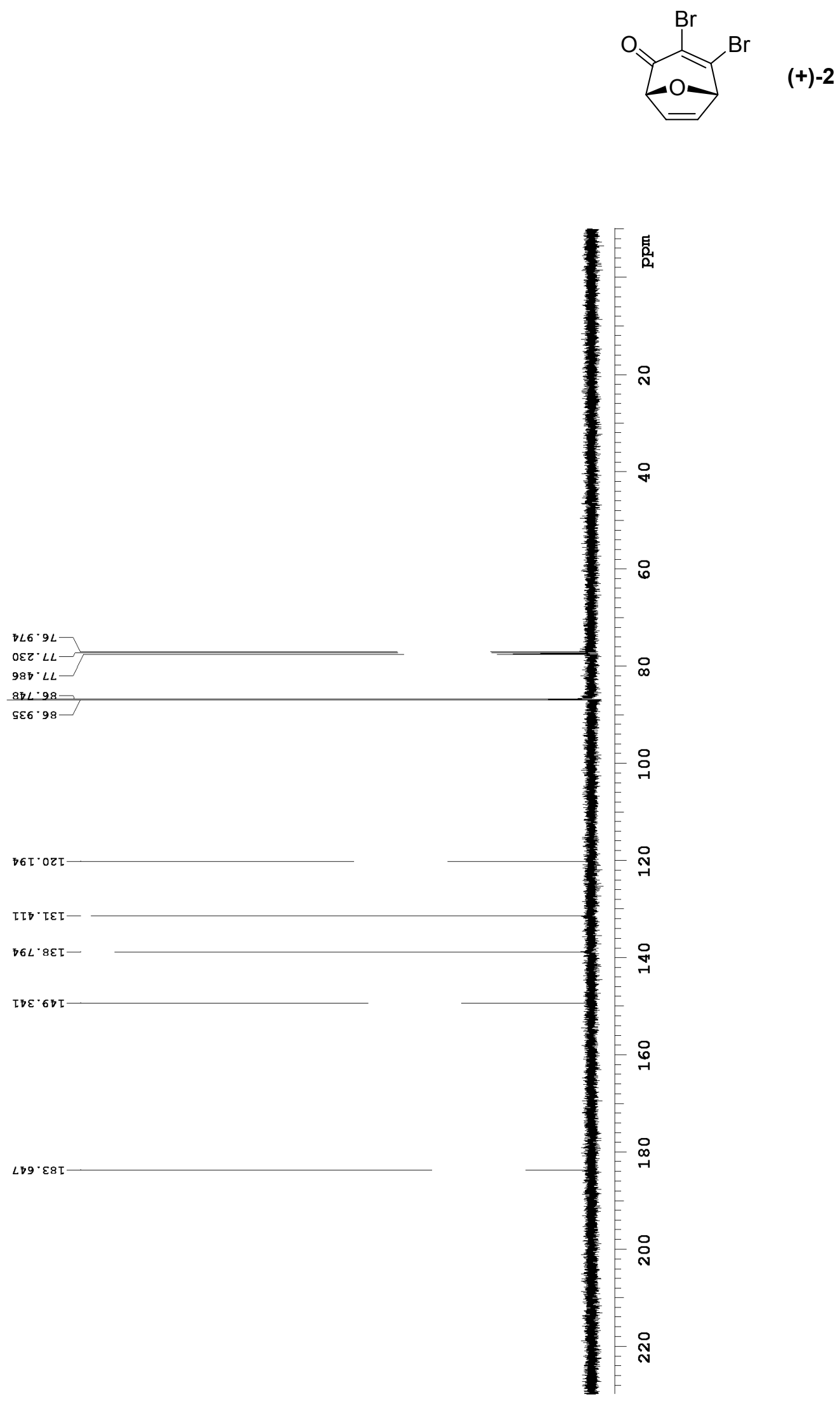

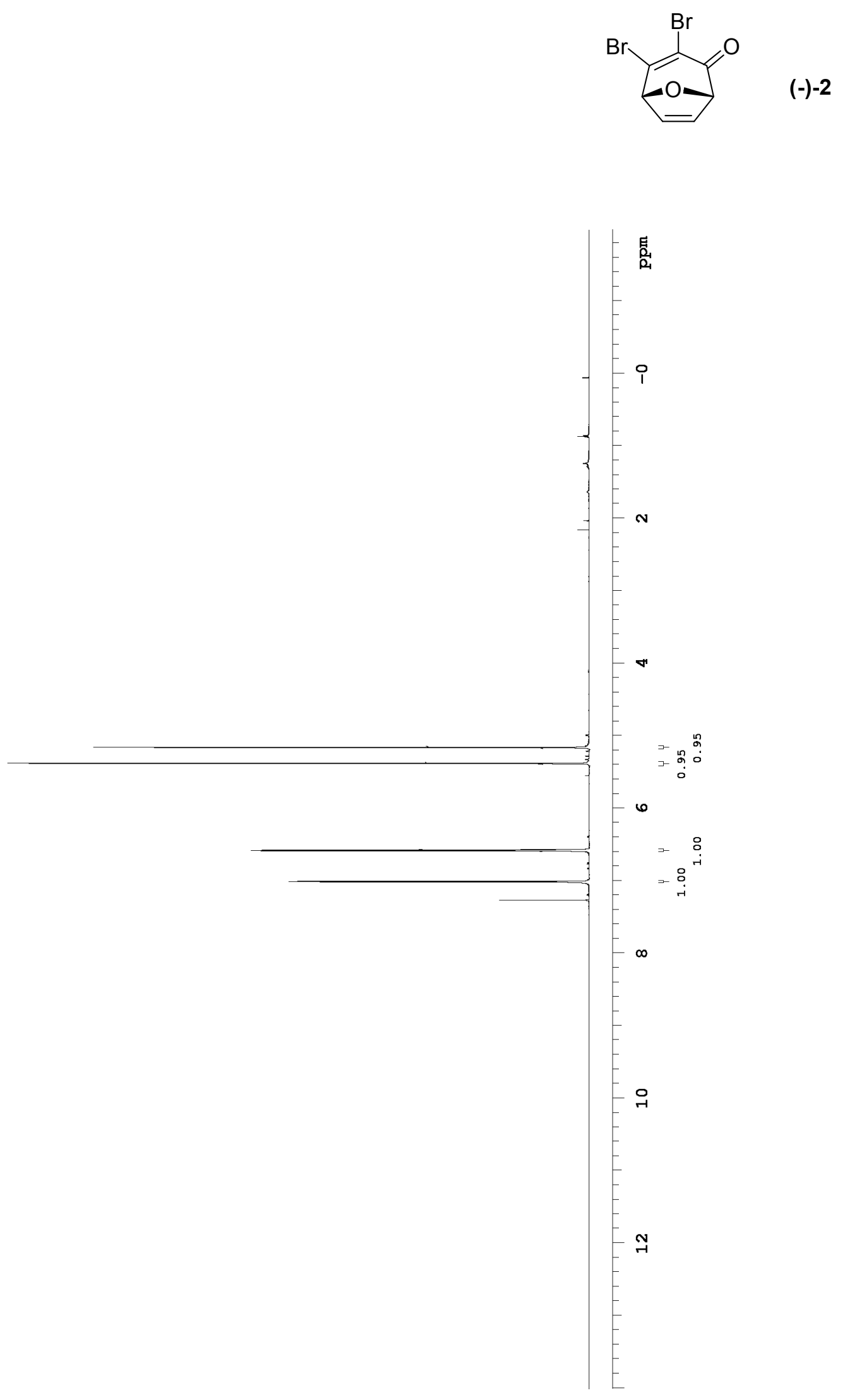


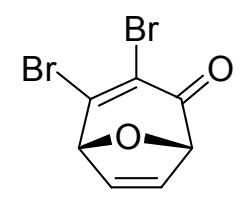

$(-)-2$

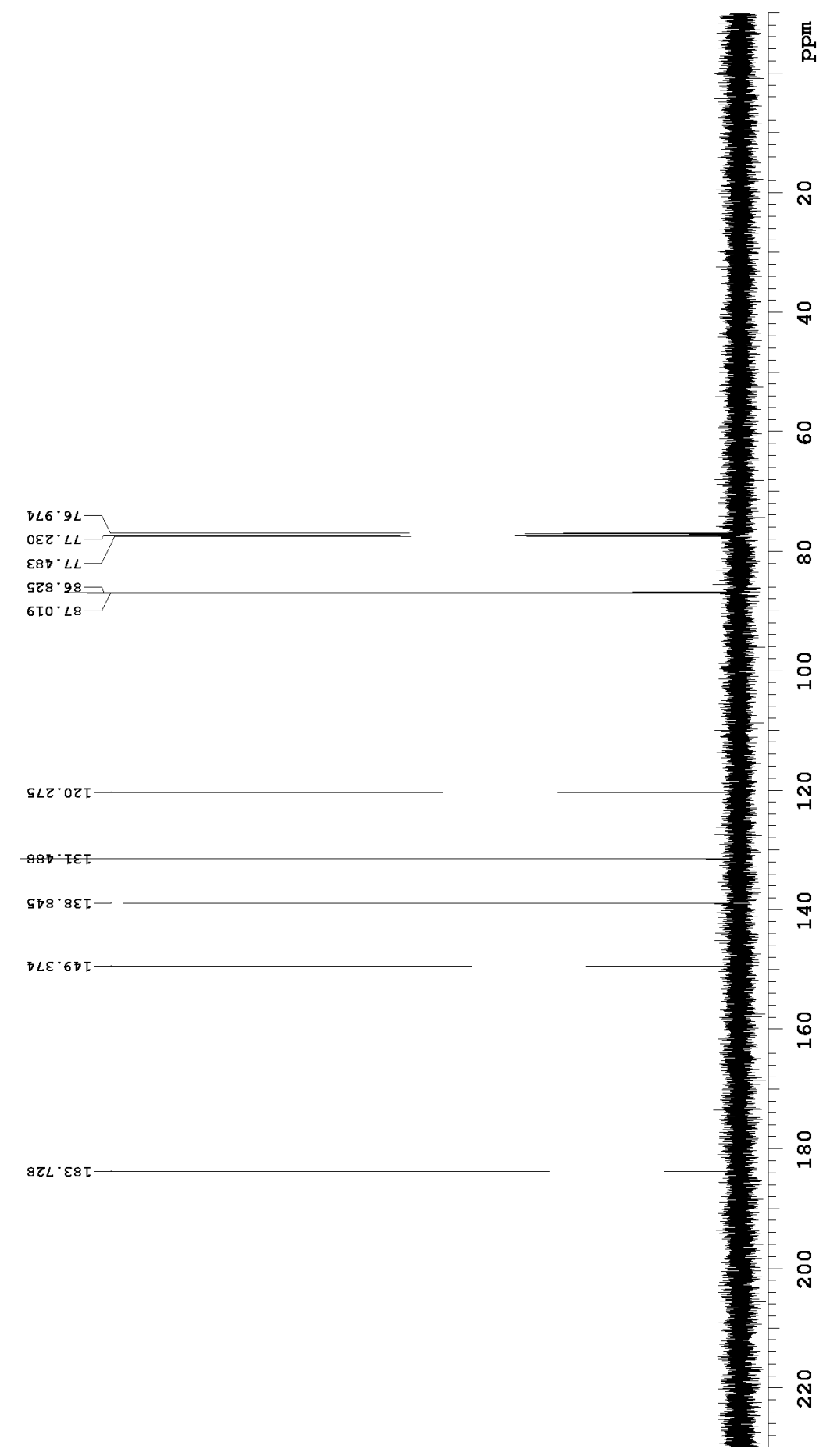

